\title{
AKCIJSKO RAZISKOVANJE KOT POT H KAKOVOSTI
}

mag. Marija

Velikonja

\section{Z boljšim razumevanjem prakse do izboljšav}

peljevanje kakovosti v izobraževalne organizacije pomeni tudi spreminjanje in izboljševanje dosedanjega dela. Zlasti vodje teh organizacij iščejo možnosti, kako narediti prve korake k spremembam, predvsem pa bi radi navdušili za spreminjanje načina dela tudi sodelavce. Vemo namreč, da se ljudje najpogosteje izogibamo spremembam tudi zato, ker od nas običajno zahtevajo več prizadevanja, kot smo ga pripravljeni sprejeti.

Ena od strategij, kako spreminjati izobraževalno prakso, je akcijsko raziskovanje. Gre za obliko razmišljajočega proučevanja, ki se ga lotevajo učitelji, da bi izboljšali svoje praktično ravnanje, razumevanje prakse in tudi objektivnih možnosti, v kateri ta poteka (povzeto po: Carr, Kemmis, 1986, v: Cerar, Požarnik, 1990, str. 67). Izobraževalne organizacije želijo na podlagi akcijskega raziskovanja:

1. izboljšati svojo prakso,

2. izboljšati razumevanje svoje prakse in

3. izboljšati razumevanje okoliščin (tudi omejitev), v katerih praksa poteka.

Začetnik akcijskega raziskovanja je socialni psiholog Kurt Lewin (1946), teorijo akcijskega raziskovanja $\mathrm{v}$ izobraževanju pa so za njim $\mathrm{v}$ sedemdesetih in osemdesetih letih razvijali zlasti Angleža Lawrence Stenhouse in John Elliot ter Američan Donald A. Schon. Pri nas jo je s pisanjem strokovnih člankov in organizacijo seminarjev že v osemdesetih letih popularizirala dr. Barica Marentič Požarnik s sodelavci (mag. Marjeta
Cerar, dr. Marija Skalar in drugi). Zlasti v zadnjem desetletju so se s takim izboljševanjem prakse seznanjali številni osnovnošolski učitelji in ravnatelji. V naši pedagoški (in tudi andragoški) praksi akcijsko raziskovanje torej ni popolna novost. Težko pa je presoditi, kako se je doslej uveljavilo $\mathrm{v}$ različnih izobraževalnih organizacijah. S prispevkom želim opozoriti na to po mojem mnenju premalo uveljavljeno pot $\mathrm{k}$ izboljšanju kakovosti dela v izobraževanju.

\section{MODEL AKCIJSKEGA RAZISKOVANIA}

Proces akcijskega raziskovanja se pri posamezniku (ali v izobraževalni organizaciji) začenja s spoznanjem, da je v njegovi (ali njihovi) praksi treba nekaj spremeniti. Učitelj (organizator izobraževanja itn.) se srečuje s problemi, nezadovoljstvom, stiskami, ki jih želi rešiti in izboljšati razmere. Na začetku presodi, na kaj je mogoče vplivati, kaj je mogoče izboljšati, potem pa se odloči za akcijo. V skladu z izhodiščno zamislijo najprej preuči razmere, opravi predhodno sondažo, potem pa izdela splošen načrt za akcijo. Akcijskega raziskovanja se lahko loti posameznik ali skupinả ljudi.

Površno bi lahko sodili, da se s postopki, ki so uveljavljeni $\mathrm{v}$ akcijskem raziskovanju, ubada vsak učitelj praktik, vendar gre pri akcijskem 
Akcijska raziskava vključuje štiri faze (Kemmis, McTaggart, 1991), to so:

1. izdelava načrta za akcijo, ki naj bi izboljšala to, kar že poteka;

2. ukrepi za uresničitev načrta;

3. opazovanje in spremljanje učinkov teh ukrepov v okvirih, znotraj katerih potekajo;

4. premislek o teh učinkih, ki je podlaga za nadalinje načrtovanje, novo akcijo. vprašanja in omejevalne dejavnike, ki so se pokazali v akciji. Spodbujajo jo pogovori med udeleženci. Pri tem učitelj (sodelavec $\mathrm{v}$ akcijski raziskavi) izkušnjo presoja in ugotavlja, ali so bili izidi akcije pričakovani in zaželeni, pa tudi možnosti za novo akcijo.

\section{NAČRTOVALNIK - VODILO ZA PRAKTIČNO DELOVANJE}

Akcijska raziskava je torej razgiban proces, v katerem so štirje postopki (načrtovanje, ukrepanje, opazovanje in refleksija) povezani $\mathrm{v}$ spiralo akcijskega raziskovanja. Raziskovalca akcijskega raziskovanja na avstralski univerzi Deakin (glej: S. Kemmis in R. McTaggart, 1991) sta za razvoj akcijskega raziskovanja $v$ praksi oblikovala poseben načrtovalnik, vodilo za praktično delovanje, ki ga tudi pri nas uporabljajo vsi, ki se preskušajo v akcijskem raziskovanju.

$\mathrm{V}$ nadaljevanju podrobneje predstavljam načrtovalnik, ki ga avtorja pojasnjujeta $\mathrm{v}$ publikaciji Kako se lotimo akcijskega raziskovanja v šoli (1991, str. 21-45).
Ukrepanje (akcija) mora biti premišljeno in kontrolirano dejanje. Načrti za akcijo so zato prožni in sprejemljivi za spremembe. Pri spreminjanju akcijske poti je treba spremljati temeljne cilje akcijskega raziskovanja: izboljšanje prakse, izboljšanje razumevanja (ose- bnega ter skupnega) in izboljšanje okoliščin, v katerih potekajo dejavnosti.

Opazovanje je načrtno. Z njim je mogoče dokumentirati učinke akcije. Opazovati in spremljati je treba akcijski proces, učinke akcije (načrtovane in nenačrtovane), okoliščine in omejevalne dejavnike ter vse drugo, kar se utegne pojaviti. Tako opazovanje vedno zahteva tudi kritično samorefleksijo.

Refleksija skuša osmisliti procese, probleme,
Slika 1: Načrłovalnik akcijskega raziskovanja

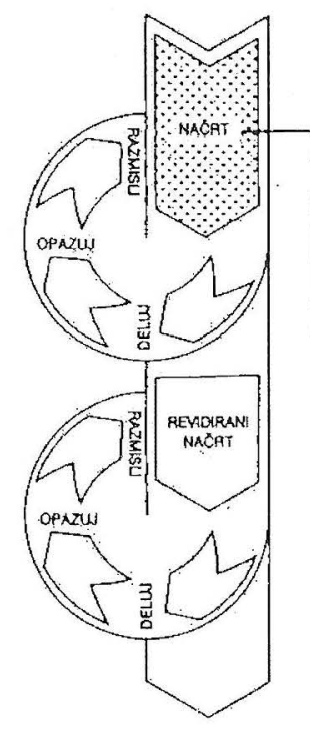




\section{Okvirna zamisel}

Učitelj (lahko tudi skupina učiteljev ali organizator izobraževanja itn.) ima največkrat vrsto zamisli, kaj bi pri svojem delu dopolnil, spremenil, izboljšal.

Ko se loteva akcijskega raziskovanja, na primer ugotovi:

- da bi (določeno) zamisel rad preskusil $\mathrm{v}$ učni skupini,

- da bi izkušnjo, ki jo je pridobil, rad prenesel na novo skupino;

ali pa se sprašuje o tem:

- kaj storiti, da bi spremenil stanje.

Konkretizirajmo probleme in zamisli za izboljšave. Učitelji, ki so poučevali brezposelne odrasle in sodelovali pri programih usposabljanja, na primer ugotavljajo, da se ti odrasli ne znajo učiti, da so nekateri preslabo motivirani za izobraževanje, da se bojijo neuspeha ipd. Ko smo njihovo učenje razčlenjevali, so učitelji med drugim poročali:

- da veliko truda potrebujejo že za to, da bi jim dopovedali, kako pomembna je urejenost zvezkov in drugih učnih pripomočkov;

- da jim je samostojno učenje tuje;

- da nimajo učnih navad;

- da le redki uporabljajo učbenik;

- da nimajo izdelanega načina učenja itn.

Organizatorji izobraževanja in tudi učitelji so tudi ugotavljali, da mnogi brezposelni odrasli, vpisani v programe, prepogosto brez posebnega razloga manjkajo pri učnih urah. Ker zagotavlja dejavno sodelovanje v izobraževanju tudi večjo uspešnost, so menili, da bi bilo treba doseči večjo udeležbo pri pouku.

Taka vprašanja in ugotovitve so učitelju (ali skupini učiteljev) in organizatorjem izobraževanja lahko izhodišče za okvirno zamisel pri akcijskem raziskovanju. Na primer, ugotavljam, da le redki udeleženci izobraževanja uporabljajo učbenik. Kako doseči, da bodo učbenik uporabljali vsi (ali večina) in da se bodo iz njega znali učiti in naučiti? Zdi se mi tudi, da nekatere predmet ne zanima, zato ne prihajajo k pouku. Kaj storiti, da bi tudi njih zainteresirali, motivirali za izobraževanje?

Omenjena avtorja opozarjata, da se je treba odločati za izpeljavo takih zamisli, ki so uresničljive, čeprav so dosežki na zunaj komaj opazni. Problem je treba torej primerno omejiti.

\section{Raziskava terena}

V tej fazi usmerjamo okvirno zamisel v akcijo. Preverimo, kaj že poteka, koga bo akcija zajela, s kom se je treba povezovati itn. Dobro si je zapisati omejitve, ki jih predvidevamo pri izpeljavi akcije, pa tudi spodbudne dejavnike. To je faza zbiranja podatkov, razlage, prepričevanja, opisovanja, dopolnjevanja, pogovorov. Svoje zamisli je dobro predstaviti sodelavcu, »kritičnimu prijateljem « in prisluhniti njihovim odzivom. Fazo končamo, ko lahko že natančno opišemo akcijo, dejavnost, ki jo načrtujemo.

\section{Polje akcije}

Dejavnost, ki jo načrtujemo, Zapis prvega akcijskega koraka omogoča natančno spremljanje.

je treba zapisati, in sicer dosedanjo dejavnost in spremembe, ki jih nameravamo izpeljati, in to tudi utemeljiti. Zapišemo tudi, kako nameravamo akcijo izpeljati, najbolje, da poiščemo za izpeljavo več poti. Presodimo in zapišemo tudi, kaj je potrebno, da bo akcijo mogoče izpeljati (ljudje, denar ipd.). Nato pa se je treba odločiti, kateri bo prvi akcijski korak, kako spremljati učinke (načrtovane ter nenačrtovane), in izdelati urnik, po katerem bo dejavnost potekala.

\section{Prvi akcijski korak}

Prvi akcijski korak je treba izdelati zelo podrobno. Zajemati mora: 


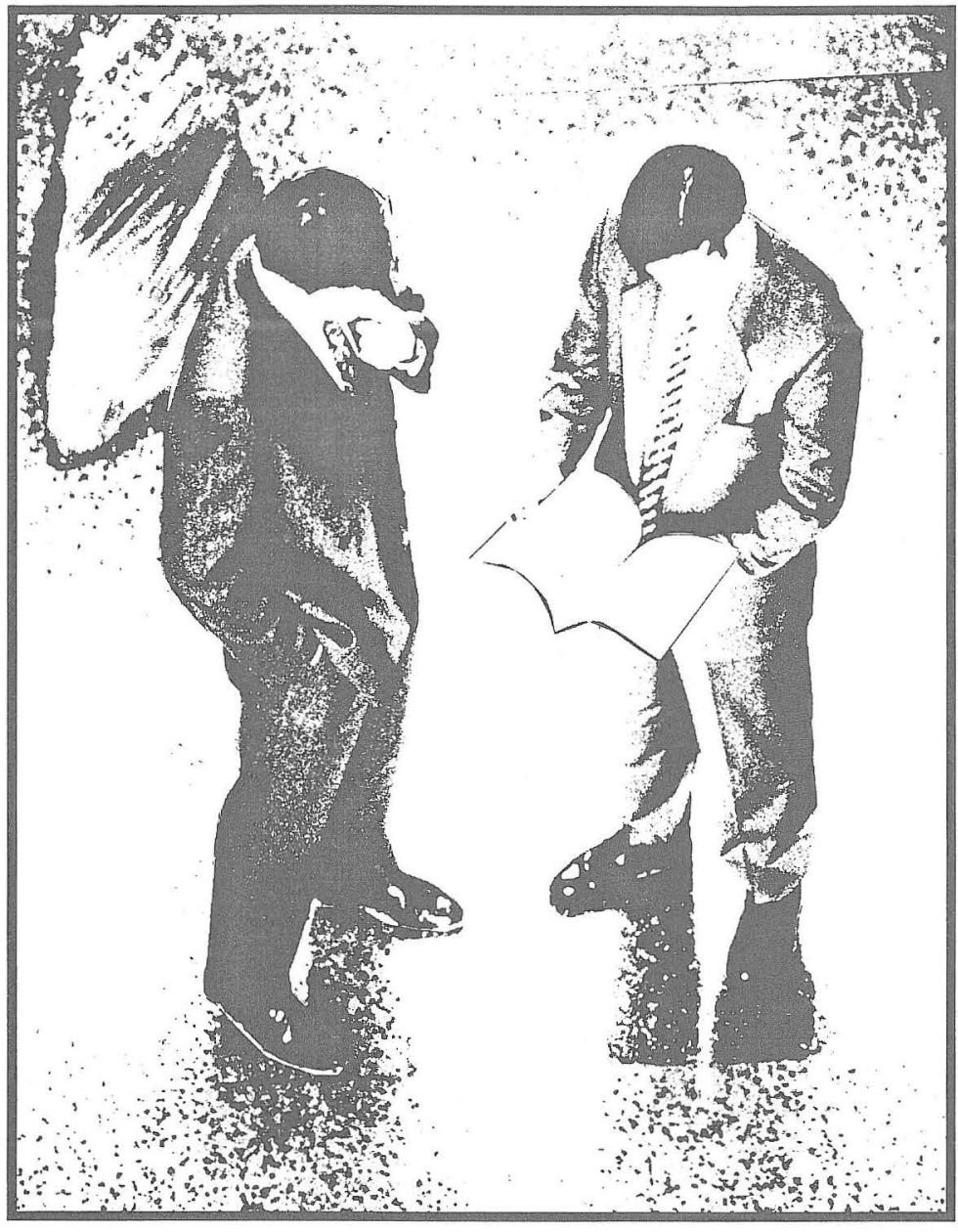

- natančen opis, kaj bomo v praksi spremenili (da ne bomo skrenili s poti);

- utemeljitev načrtovane strateške akcije; zapišimo razloge, zakaj je akcija strateška: želi izboljšati prakso in možnosti, predvideva boljše razumevanje prakse, razmer; predvidimo, kako bo akcija vplivala na udeležence, učenje, organizacijo itn.;

- učinke; zapišimo učinke, ki jih nameravamo doseči z akcijo, pozitivne in negativne, pa tudi morebitne stranske učinke; kako se bomo odzvali na morebitne negativne učinke;

- osebe, ki jih akcija vključuje ali jih neposredno zadeva; zapišimo, katere so te osebe, kako so vključene v akcijo, opredelimo njihovo vlogo pri prvem akcijskem koraku;
- zagotovitev sredstev (gradivo, prostori, oprema in drugo);

- ovire in probleme, ki jih pričakujemo.

Opis prvega akcijskega koraka je zelo pomemben, saj se nenehno vračamo na začetek, zapisujemo in kasneje vnašamo izboljšave tudi za nazaj.

\section{Spremljanje}

$\mathrm{S}$ spremljanjem pridobivamo informacije o tem, kako je akcija potekala. Tako lahko analiziramo dosedanje delo, bolje razumemo in izboljšujemo strateške akcije v nadaljnjih korakih. $\mathrm{V}$ tej fazi sodelavec akcijske raziskave odgovarja na vprašanja, ki zadevajo strateško akcijo kot proces (ali smo uresničevali tisto, kar smo načrtovali), posledice strateške akcije (kateri so bili načrtovani in pričakovani, pa tudi nenačrtovani, nepričakovani učinki), okoliščine strateške akcije (ali so bili upoštevani socialni in drugi dejavniki, kako so se spremenile okoliščine itn.).

Akcijo moramo spremljati iz vseh zornih kotov (mnenje raziskovalca, učencev, kolegov, ravnatelja itn.).

Metode in tehnike zbiranja podatkov v akcijskem raziskovanju (tudi $\mathrm{v}$ fazi spremljanja) so, v nasprotju z zbiranjem kvantitativnih podatkov pri tradicionalnem raziskovanju, pretežno kvalitativne, na primer pisanje dnevni$\mathrm{ka}$, na pol vodeni ali prosti intervjuji, anketni vprašalniki $\mathrm{z}$ odprtimi odgovori, zapisi in različni izdelki udeležencev izobraževanja, fotografski, avdio in video posnetki, zapisniki sestankov, analiza skupinskega dogajanja itn.

\section{Časovni razpored}

Akcijo je treba časovno podrobno razčleniti. Izdelati je treba informativni urnik, vanj vpisati vse predvidene faze akcije in jih časovno določiti, vpisati dejavnosti, akcijske korake, njihovo trajanje, pripomočke, ki jih bomo potre- 
bovali, itn., kajti šele tako podrobno razčlenjeno aktivnost je mogoče tudi časovno spremljati.

Ko je izdelan splošni načrt, ga pred izpeljavo prvega akcijskega koraka še enkrat preverimo, nato začnemo akcijo: ukrepamo, spremljamo, zapisujemo, sodelujemo, kritično premišljamo, spreminjamo, dopolnjujemo aktivnost itn.

\section{SKLEPNO POROČILO}

Strokovnjaki so ugotovili (Argyris in sodelavci, 1985, v: Altrichter, Posch, 1991), da si praktik v akcijskem raziskovanju ne zastavlja vprašanja, ali smo dosegli zastavljene cilje, temveč se sprašuje o tem, ali nam ugaja to, kar smo dobili. S tem vključuje v proces razmišljanja in spreminjanja tudi svoje vrednostne predstave.

$\mathrm{V}$ sklepnem poročilu naj bodo zapisane tudi ideje, kako ravnati v naslednjem ciklu, in premisleki, kako spremeniti postopke že izpeljane akcije, če bi medtem ugotovili boljše poti do zastavljenega cilja.

Zapis o akcijski raziskavi je namenjen predvsem učitelju - raziskovalcu, pri tem namreč ponovno premišlja o svojih korakih, in prav to ga sili k temu, da bi pridobljene izkušnje uporabil v novih okoliščinah.

Akcijska raziskava je nekakšna študija primera, pri katerem ni možno popolno posploševanje. Za tistega, ki izpelje akcijsko raziskavo, pa so njene sklepne ugotovitve vsekakor dragocen dokument in vodilo pri nadalinjem delu. Sklepno poročilo naj bo torej skrbno zapisano in naj ne zajema le formalnih podatkov, temveć naj bo sporočilo o tem, kako se je splošna ideja v procesu razvijala in spreminjala, kako se je odzivalo okolje, o posledicah akcije, vlogah udeležencev, problennih, ki so se pojavljali, izboljšavah v praksi in razumevanju prakse, mnenje o odzivih učencev itn.

\section{PREDNOSTI AKCIJSKEGA RAZISKOVANJA}

Strokovnjaki, ki razvijajo in spodbujajo akcijsko raziskovanje, navajajo njegove številne prednosti v praksi. Navajam le nekatere:

1. Akcijsko raziskovanje zahteva uveljavljanje demokratičnih načel v raziskovanju. Vsak posameznik je enakovreden član skupine raziskovalcev, akcijsko raziskovanje pa je sodelovalen, participatoren proces, individualen je le takrat, kadar posameznik raziskuje in spreminja lastno prakso.

2. Akcijsko raziskovanje spodbuja profesionalnost učitelja, izobraževalca in vseh, ki se lotevajo takega raziskovanja. Če se strinjamo s trditvijo, »da je najbolj očitna značilnost profesionalca sposobnost avtonomnega poklicnega razvoja s sistematičnim študijem svojega dela, s študijem dela drugih učiteljev in $s$ preverjanjem pedagoških idej $\mathrm{z}$ raziskovanjem $\mathrm{v}$ Akcijsko raziskova-
nje spodbuja
poklicni razvoj
izobraževalca. razredu« (Altrichter, Posch, 1991), ki jo je mogoče prenesti tudi $v$ procese izobraževanja odraslih, se prav v procesih akcijskega raziskovanja oblikuje pričakovana profesionalnost. Razvija se tip izobraževalca, ki »razmišlja $\mathrm{v}$ delovanju«, in takega, ki »razmišlja o delovanju«.

3. Pri akcijskem raziskovanju se učitelj - raziskovalec srečuje s sodobnimi tehnikami spremljanja, kot so anekdotični zapiski, terenski zapiski, ekološki (celostni) zapis obnašanja, analiza dokumentov, dnevniki, delovni koledarji, kartotečne kartice, mape, pogovori, avdio ali video zapisi, fotografije in diapozitivi, seveda pa so včasih potrebni in uporabni tudi vprašalniki, testi znanja itn.

4. Akcijsko raziskovanje je tako tudi učinkovita pot $\mathrm{k}$ izboljšanju kakovosti dela posameznega učitelja - izvajalca izobraževanja 
ali vodje izobraževanja, če se za ta korak (hkrati z izvajalci) odločajo tudi vodstveni in vodilni delavci v izobraževalni organizaciji. To ni pot, s katero bi bilo mogoče hitro zablesteti in se povzpeti v odličnost, temveč zanesljiva smer, ki dolgoročno vodi kolektiv in posameznike $\mathrm{k}$ procesom nenehnega izboljševanja njihovega dela.

\section{SKLEPNE MISLI}

$\mathrm{V}$ preteklih letih so se učitelji in vodstveni delavci v osnovnih in srednjih šolah na seminarjih odločali za teme, kot so hišni red šole, urejanje bivalnega okolja, oblikovanje kohezivnih skupin, uvodna motivacija učencev, sporočanje $\mathrm{v}$ materinščini, razumevanje branja, napovedano ustno spraševanje itn. Avtorja Altrichter, Posch (1991, str. 19) na primer opisujeta primer »zadeva $\mathrm{z}$ domačimi nalogami«. Gre torej za vprašanja organizacije in pedagoškega dela v šolah ali probleme izpeljave izobraževalnega programa in drugih dejavnosti v razredu.

Tudi v izobraževanju odraslih so številne teme (s področja andragoškega vodenja, organizacije ali izboljšav v učenju in izobraževanju odraslih), ki bi jih lahko spreminjali z akcijskim raziskovanjem. Znova in znova se srečujemo z novimi izzivi in prakso, s katero nismo povsem zadovoljni. Akcijsko raziskovanje je ena od poti $\mathrm{k}$ izboljševanju prakse in $\mathrm{s}$ tem $\mathrm{k}$ večjemu profesionalnemu delovanju.

Vodje izobraževanja odraslih lahko postanejo pobudniki in spodbujevalci takega raziskovanja v svojih institucijah. Po njih se bodo zgledovali tudi učitelji - izvajalci izobraževanja in drugi.

\section{LITERATURA}

Altrichter, H., Posch, P. (1991). Učitelji raziskujejo svoj pouk. Vzgoja in izobraževanje, letnik 22, št. 2, str. $12-22$.
Akcijsko raziskovanje v vzgoji in izobraževanju (1990). M. Cerar, B. Marentič Požarnik (ur.). Ljubljana: Slovensko društvo pedagogov.

Akcijsko raziskovanje. Gradivo s seminarjev Zavoda RS za šolstvo v letih 1990-1994.

Kemmis, S., McTaggart, R., Marentič Požarnik, B., Skalar, M.(1991). Kako se lotimo akcijskega raziskovanja v šoli (1991). Ljubljana: Slovensko društvo pedagogov in Didakta.

Marentič Požarnik, B. in drugi (1993). Okolje in šolske iniciative: zgodba nekega projekta. Ljubljana: Zavod RS za šolstvo. 